\title{
The Statistical Power in the Study of Onset and Duration of Rocuronium in Hyperthyroidism and Euthyroidism Patients
}

Dear Editor,

We read the interesting paper by Wang et al (1) in the Journal. The authors conclude that; hyperthyroidism patients experience a shorter onset time, a shorter duration, and require larger doses of rocuronium than euthyroidism patients. This conclusion was based on the data generated from 17 patients in each study group. The onset time was $56 \pm 10$ and $71 \pm 13 \mathrm{~s}$, and the $1 \mathrm{st} T 25$ was $17 \pm 5$ and $31 \pm 8 \mathrm{~min}$ for hyperthyroidism and euthyroidism patients, respectively.

Although these results are statistically significant, we think that the power of the study has been overlooked. This measurement are associated with great variations so that even in standardized, controlled studies on non-depolarizing neuromuscular blockers the outcome such as, the onset time and duration of action may show four to six fold differences $(2,3)$. A recent similar study that aimed to investigate the influence of gender on rocuronium-induced neuromuscular block, the authors calculated 120 patients in each group to be sufficient to find a significant difference of $10 \%$ or more in clinical duration between groups $(0.05$ twosided significance level $[\alpha=0.05], 80 \%$ power $[\beta=0.2])(3)$. We believe that assessments with TOF measurement show high standard deviation, therefore power studies should be conducted before the studies for more reliable results.

Seza Apiliogullari, Ates Duman, Cemile Ogun, Funda Gok

Corresponding Author: Seza Apiliogullari MD, Dr. Faruk Sukan Obstetrics and Children Hospital, Department of Anaesthesia and Intensive Care, Konya, Turkey. sapiliogullari@yahoo.com

\section{REFERENCES}

1. Wang YG, Song XJ, Feng SW, Ge YL, Yang JJ, He LL. Hyperthyroidism Patients Have Shorter Onset and Duration Time of Rocuronium than Euthyroidism Patients. J Pharm Pharmaceut Sci, 2007, 10:53-60.

2. Apiliogullari S, Okesli S, Reisli R, Duman A, Ogün $\mathrm{CO}$. Effects of nondepolarizing muscle relaxants mivacurium and rocuronium on neuromuscular blockade and intubation conditions in children. (Turkish) Genel Tip Derg 2006; 16: 153-159.

3. Adamus M, Koutna J, Gabrhelik T, Hubackova M, Janaskova E. Influence of gender on the onset and duration of rocuronium-induced neuromuscular block. Biomed Pap Med Fac Univ Palacky Olomouc Czech Repub. 2007; 15: 301-305.

\section{Response}

\section{Dear Editor}

Dr. Apiliogullari et al. suggestion is reasonable. However, we do not totally agree with their conclusion: First, our study was a preliminary one. Sample size calculation is usually necessary for a confirmatory study. In our paper (1), we did state that a search in PubMed yielded no report concerning the pharmacodynamics of rocuronium in hyperthyroidism patients and our investigation was preliminary in nature. Second, statistical power reflects the probability of rejecting the null hypothesis when it is false. Since we noticed such a significant difference between the two groups, the issue of additional power became moot. Third, for a future study on the pharmacodynamics of rocuronium or other nondepolarizing neuromuscular blocking agents in hyperthyroidism patients, the sample size calculation can be made using our primary results. For example, according to the onset time of $56 \pm 10 \mathrm{sec}$ vs. $71 \pm 13 \mathrm{sec}$, we calculate the required sample size to be 10 patients in each group with $\alpha=0.05$ (two tailed), $\beta=0.2$. This calculation implies that the sample size of 17 patients/group provided sufficient power to our statistical analysis.

Jian-jun Yang, Yu-xiu Liu, Xiao-li Xu,,Yongguang Wang,

Corresponding author: Dr. Jian-jun Yang, Department of Anesthesiology, Jinling Hospital, Nanjing University, Nanjing, P.R. China. yjyangjj@126.com

\section{REFERENCE}

1. Wang YG, Song XJ, Feng SW, Ge YL, Yang JJ, He LL. Hyperthyroidism Patients Have Shorter Onset and Duration Time of Rocuronium than Euthyroidism Patients. J Pharm Pharmaceut Sci, 2007, 10:53-60. 